\title{
Transport of Phenol in BS-12 Modified Lou Soil in the Column Experiment: Effect of Concentrations, pH and Ionic Strength
}

\author{
Sambath Yek ${ }^{1}$, Lingkai Zhang1, Zhaofu Meng',2, Soklun Heng1, \\ Shuaibin Bu1, Haoyuan Lu', Mengfei Zhang1 \\ ${ }^{1}$ College of Natural Resources and Environment, Northwest A\&F University, Xianyang, China \\ ${ }^{2}$ Key Laboratory of Plant Nutrition and Agri-Environment in Northwest China, Ministry of Agriculture, Xianyang, China \\ Email: yek_sambath@yahoo.com,zfmeng1996@263.net, sddyzlkdmc@163.com
}

How to cite this paper: Yek, S., Zhang, L.K., Meng, Z.F., Heng, S., Bu, S.B., Lu, H.Y. and Zhang, M.F. (2019) Transport of Phenol in BS-12 Modified Lou Soil in the Column Experiment: Effect of Concentrations, $\mathrm{pH}$ and Ionic Strength. Journal of Water Resource and Protection, 11, 540-553. https://doi.org/10.4236/jwarp.2019.115031

Received: May 6, 2019

Accepted: May 18, 2019

Published: May 21, 2019

Copyright $\odot 2019$ by author(s) and Scientific Research Publishing Inc. This work is licensed under the Creative Commons Attribution International License (CC BY 4.0).

http://creativecommons.org/licenses/by/4.0/

(c) (i) Open Access

\begin{abstract}
Lou soil was modified by amphoteric surfactant in column experiment which was conducted. This study attempts to explore the transport of phenol to unmodified and modified soil and inquire into the effect of concentrations, $\mathrm{pH}$, and ionic strength on phenol migration in the soil column. The parameters and breakthrough curves (BTCs) of transport were fitted by using the CXTFIT (version 2.1) model. The result of $\mathrm{Cl}^{-}$s BTCs for non-reactive by determining the equilibrium model (EM) showed the retardation factor which was smaller than 1 . The result of phenol's BTCs by determining non-equilibrium model (NEM) was shown that the $R$-value increased while modification ratio increased, and the $R$ was in order of CK $(1.337)<50 \mathrm{BS}-12(4.085)<100 \mathrm{BS}-12$ (7.048). The lower to higher concentration of phenol didn't affect to CK and 100BS-12 was able to block higher concentration. The effect of $\mathrm{pH}$ on transport to CK and 100BS-12 didn't react and the average pore water velocity was decreased at $\mathrm{pH}=4$. The decreasing ionic strength of phenol migration on CK and 100BS-12 had effect and the average pore water velocity and retardation factor also decreased. The residual retention in soil was in order of CK $<50 \mathrm{BS}-12<100 \mathrm{BS}-12$, and 100BS-12 could hold the amount of phenol than CK 7.21 times. Thus, amphoteric modified lou soil definitely blocks phenol migration and controls groundwater pollution.
\end{abstract}

\section{Keywords}

Amphoteric Modifier (BS-12), Modified Soil, Phenol, BTCs, Concentrations, $\mathrm{pH}$, Ionic Strength, Residual Retention

\section{Introduction}

According to the main environmental elements constituting the ecosystem, the 
important materials that we live on earth is soil [1]. However, the environmental soil is becoming unsafety by natural form and human activities and heavy metals and organic pollutant (phenol, PAH, etc.) in the soil has become an environmental issue. As known heavy metal and organic pollutant were found together; therefore the main of organic pollutant with high priority is phenolic compound [2]. Phenol is counted as high toxicity pollutant and affected human health while it has gradually accumulated in the environment [3] [4]. In that case, phenol is generated and discharged from industrial wastewater, after that phenol movement progressively penetrates in environmental soil and groundwater while it is dumped to pond tailing [5].

To prevent groundwater contamination, the research on the remediation soil was conducted. At present, the soil and clay mineral were modified by surfactant agents to enhance adsorption capacity [6] [7] [8] [9]. As known the lou soil is the main agricultural soil with high organic carbon. It was studied to modify with surfactant agent to protect the soil environment [10]. Meng et al., 2008 and Bai et al., 2010 studied using of amphoteric surfactant to modify lou soil and the result indicated that the phenol adsorption capacity of modified soil increased while modification ratios increased [11] [12]. However, the studies on the solute transport by transporting of phenol through the soil were meagerly conducted. Previous studies mostly emphasized the soil was able to enhance its ability to prevent and control pollutant and result showed that the natural soil had the poor ability to block phenol [13] [14]. Therefore, transport of phenol through amphoteric modified lou soil was not conducted yet.

According to previous studies, the environmental factor as $\mathrm{pH}$ of solute transport of heavy metal was conducted [15] [16] [17]. This is because the $\mathrm{pH}$ is also the main factor in solute transport. By the way, the effect of $\mathrm{pH}$ and ionic strength on the transport of phenol through the soil, limited research has carried out [18]. However, Effect of concentrations, $\mathrm{pH}$, ionic strength on phenol transport through amphoteric modified soil has not reported yet.

Due to breakthrough curve analyzed by Convection-Dispersion Equation (CDE) in CXTFIT (version 2.1) model [19] of STANMOD [20] program, many researchers used this model to predict heavy metal and organic pollutants transport [14] [21] [22]. The main parameter for indicating the rate pollutant migration is retardation factor $(R)$ and it can emphasize equilibrium and non-equilibrium model. For example, Huang et al., 2009, Yang et al., 2009 and Di et al., 2015 studied using CXTFIT (version 2.1) model by estimating retardation factor $(R)$ value for analysis through the equilibrium model for making the breakthrough curve of tracer $\mathrm{Cl}^{-}$and non-equilibrium model for making the breakthrough curve of heavy metal and organic pollutant transportation was reasonably fitted [15] [18] [23].

The objective of this research is to attempt the fate and transport of phenol through amphoteric modified soil and effect of concentration, $\mathrm{pH}$, and ionic strength by using CXTFIT (version 2.1) model to predict retardation factor $(R)$ 
value of pollutant migration in unmodified soil and amphoteric modified soil.

\section{Materials and Methods}

\subsection{Preparation and Property of Amphoteric Modified Soil}

The sample as lou soil was collected at uphill about $2 \mathrm{~km}$ far from the north campus of Northwest A\&F University, Yangling, Shaanxi Province, China. The lou soil was air-dried and passed through a 10 mesh nylon sieve. The Cation Exchange Capacity (CEC) of soil is $178.49 \mathrm{mmol} / \mathrm{kg}$.

AR-grade BS-12 (Dodecyl dimethyl betaine) surfactant in this experiment was provided by Xingguang Auxiliary Factory, Tianjin City, China. The molecular structure of amphoteric modifier was shown in Figure 1.

The weight of soil was modified by dodecyl dimethyl betaine (BS-12) equivalent $50 \%$ and $100 \%$ as analytical reagent with $30 \%$ (W/V) through calculating with Cation exchange Capacity (CEC) of lou soil. Firstly, the BS-12 was dissolved with deionized water between soil's weight and deionized water [1:10] at $40^{\circ} \mathrm{C}$, and added soil under being stirred for $3 \mathrm{~h}$. Then the sample was centrifuged and washed 3 times with deionized water, dried at $60^{\circ} \mathrm{C}$ and passed through 10 mesh sieves.

The amount of modification of BS-12 was calculated according to the following formula:

$$
W=m \times C E C \times M \times 10^{-6} \times R / b
$$

where: $W$ is the quality of the modifier, (g); $m$ is the mass of the soil sample, (g); $C E C$ is the cation displacement of the modified soil sample, $(\mathrm{mmol} / \mathrm{kg}) ; M$ is the molar mass of the modifier, $\mathrm{g} / \mathrm{mol}$; $b$ is the modifier product content (BS-12 take 30\%).

\subsection{Experimental Design}

The transport experiment was conducted saturated-column and column was 5 $\mathrm{cm}$ in length and $5 \mathrm{~cm}$ diameter with a thickness of $0.5 \mathrm{~cm}$. The two covers of the column were one hole to let solution flow in and out for testing concentration. To place 1000 mesh sieve filters in the top and bottom of the column was to protect falling down of soil. In the experiment, the head pressure of moving liquid was set $1.5 \mathrm{~cm}$ and was controlled the distance between the level surface of the big bottle at the top and level surface of the column. The soil in the column was prepared as unmodified soil (CK), 50BS-12 modified soil (50BS-12), and 100BS-12 modified soil (100BS-12). The basis parameters of unmodified and modified soils were listed in Table 1.

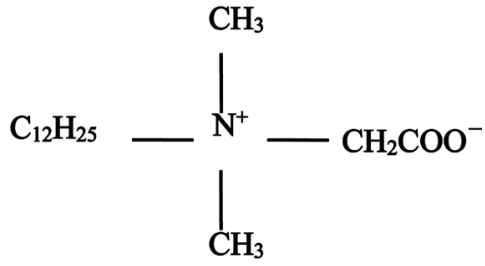

Figure 1. The amphoteric surface modifying agent, dodecyl dimethyl betaine (BS-12). 


\subsubsection{Effect of Concentrations, $\mathrm{pH}$, and Ionic Strength on the Transport of Phenol}

Unmodified soil and 100 BS-12 modified soil was selected to transport environmental factor such as:

Concentration was set $50 \mathrm{ppm}, 200 \mathrm{ppm}$, and $500 \mathrm{ppm}$, and controlled by ionic strength $0.1 \mathrm{~mol} / \mathrm{l}$ and $\mathrm{pH}=7$.

$\mathrm{pH}$ was set 4,7 and 10, and controlled by $50 \mathrm{ppm}$, ionic strength $0.1 \mathrm{~mol} / \mathrm{l} \mathrm{Io}$ nic strength was set $0.1,0.01$, and $0.001 \mathrm{~mol} / \mathrm{l}$ and controlled by $50 \mathrm{ppm}$ and $\mathrm{pH}$ $=7$.

\subsubsection{The Step of Experiment and Determination}

The column experiment was managed $0.1 \mathrm{~mol} / \mathrm{l} \mathrm{NaCl}, 50 \mathrm{ppm}$ of phenol with $\mathrm{pH}=7$. The first of all, supplying deionized water with slow flow rate was to entrap air from the bottom until top layer of soils in column (CK, 50BS-12 and 100BS-12) and waiting one day for making sure no bubble air existed. The next step, applying $0.1 \mathrm{~mol} / \mathrm{L}$ of $\mathrm{NaCl}$ as tracer element injected in all columns from the top and let $\mathrm{NaCl}$ solution leaching, then effluent of $\mathrm{Cl}^{-}$was collected every $10 \mathrm{ml}$ and determined $\mathrm{Cl}^{-}$. When $\mathrm{Cl}^{-}$concentration of outlet reached equal to the injected one, changing and injecting phenol $+0.1 \mathrm{~mol} / \mathrm{l}$ of $\mathrm{NaCl}$ was applied on the top of the column. The effluents were collected every $50 \mathrm{ml}$ and tested phenol concentrations reach until inlet one. The water flow was replaced again with a $0.1 \mathrm{~mol} / \mathrm{l}$ of $\mathrm{NaCl}$ solution as washout phenol, and the outlet was also collected every $50 \mathrm{ml}$ and tested pollutant until zero concentration.

The concentration of $\mathrm{Cl}^{-}$was determined by using a chlorine electrode method (Sanxin MP523).

The concentration of phenol solution was determined by 4 -aminoantipyrine spectrometry with SP-1600 UV-VIS spectrophotometer.

\subsection{Model and Data Analysis}

This experiment was used Convection Dispersion Equation (CDE) for studying the transport of $\mathrm{Cl}^{-}$and phenol:

$$
R \frac{\partial c}{\partial t}=D \frac{\partial^{2} c}{\partial z^{2}}-v \frac{\partial c}{\partial z}
$$

where $C$ is pollutant concentration ppm $(\mathrm{mg} / \mathrm{l}), t$ is time transportation $(\mathrm{h}), z$ is vertical depth $(\mathrm{cm}), D$ is dispersion coefficient $\left(\mathrm{cm}^{2} / \mathrm{h}\right), v$ is the average of pore water velocity $(\mathrm{cm} / \mathrm{h}), v=q / \theta_{s}$, where $q$ is water flux in unit area $(\mathrm{cm} / \mathrm{h})$, and $\theta_{s}$ is soil porosity.

$R$ is a retardation factor to indicate linear equilibrium adsorption transport as:

$R=1$ no interaction between soil and solutes;

$R<1$ ion exclusion;

$R>1$ chemical reaction-adsorption;

Using the STANMOD program by CXTFIT (version 2.1) model was determined the parameter in experiment $v, D$ and $R$ are fixed for transporting $\mathrm{Cl}^{-}$and phenol. 
Using CURVEEXPERT software was simulated penetration of curve phenol such as saturation amount, washout amount, the residual amount (saturation amount-washout amount), residual retention (residual amount/soil's weight in the column) and holding rate (residual amount/saturation amount).

\section{Results and Discussion}

\subsection{Effect on the Transport of $\mathrm{Cl}^{-}$on Unmodified Soil and Modified Soil}

The Breakthrough Curves (BTCs) of $\mathrm{Cl}^{-}$was shown and it was plotted between concentration $(\mathrm{C} / \mathrm{Co})$ and pore volume $(\mathrm{V} / \mathrm{Vo})$ in Figure 2. The parameter of $D$ and $R$ of $\mathrm{Cl}^{-}$was fitted by using the equilibrium model (EM) and $R^{2}>0.99^{* * *}(\mathrm{P}$ $<0.01$ ) in Table 2 . The order of $v$ average pore water velocity of $\mathrm{Cl}$-migration in soil was $\mathrm{CK}>100 \mathrm{BS}-12>50 \mathrm{BS}-12$ and the order of $D$ value was $\mathrm{CK}>$ 100BS-12 > 50BS-12. Linear correlation equation between $V$ and $D$ of BS-12 modified soil was $D=0.4432 v+0.578, R^{2}=0.8239$, so it indicated that $v$ and $D$ value have related each other to the physical structure the soil column after modification [18] [23]. Therefore, the flow velocity was decreased gradually and the $D$ value becomes smaller, respectively. The retardation factor $R$-value of $\mathrm{Cl}^{-}$

Table 1. The basic parameters of unmodified and modified soils.

\begin{tabular}{cccccc}
\hline Soils & $\mathrm{pH}$ & $\begin{array}{c}\text { Bulk density } \rho_{d} \\
\left(\mathrm{~g} / \mathrm{cm}^{3}\right)\end{array}$ & $\begin{array}{c}\text { Density } \rho \\
\left(\mathrm{g} / \mathrm{cm}^{3}\right)\end{array}$ & Porosity & $\begin{array}{c}\text { The velocity } \\
\text { of flow }(\mathrm{ml} / \mathrm{h})\end{array}$ \\
\hline CK & 8.54 & 1.353 & 1.798 & 0.247 & 33.222 \\
50BS-12 & 8.82 & 1.270 & 1.704 & 0.252 & 14.362 \\
100BS-12 & 8.91 & 1.320 & 1.765 & 0.251 & 16.132 \\
\hline
\end{tabular}

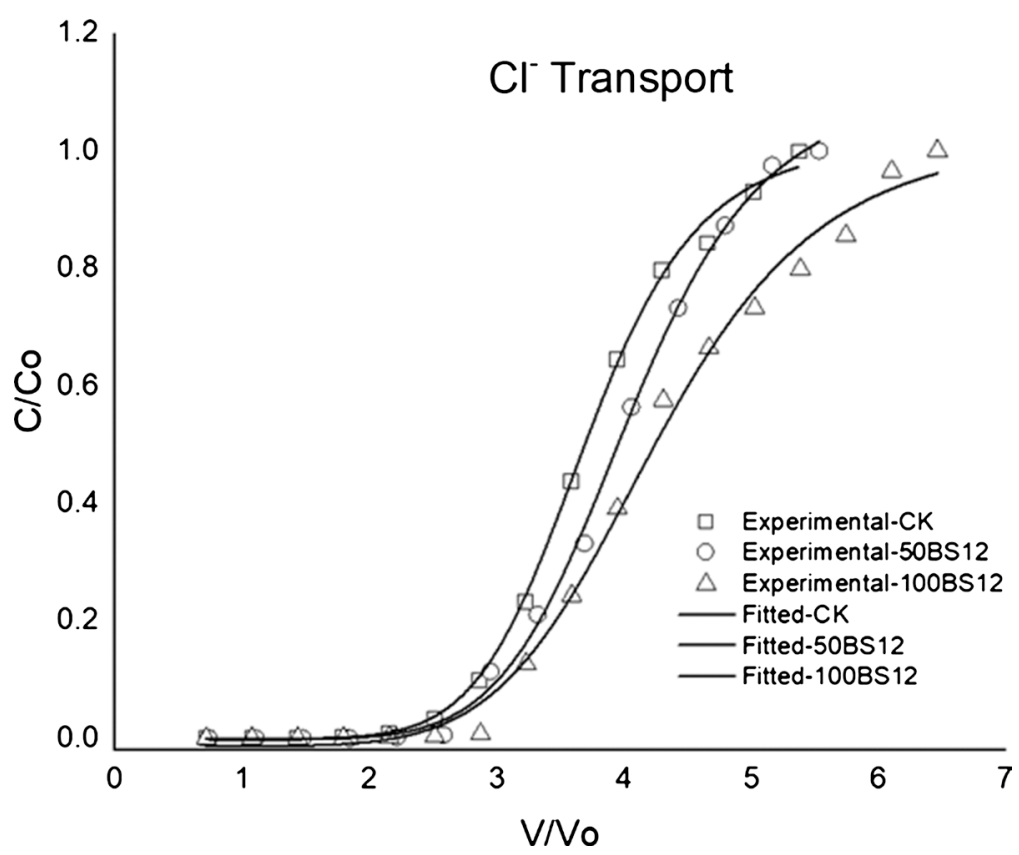

Figure 2. The BTCs of $\mathrm{Cl}^{-}$in CK, 50BS-12 and 100BS-12. 
in Table 2 showed in order of 100BS-12 > 50BS-12> CK and all $R$-value were smaller than 1 . So that, it indicated that the transport of $\mathrm{Cl}^{-}$was non-reactive ion in the soils as the same result [15] [18] [23].

\subsection{Effect of the Transport of Phenol in Unmodified Soil and Modified Soil}

The BTCs of transport and washout of phenol in different modified soil were shown in Figure 3, and the result of parameter $D$ and $R$ from fitting the BTCs by the non-equilibrium model (NEM) of CXTFIT model was shown in Table 3. The number pore volume (NPV) of phenol migration was 17.89 (CK), 29.65 (50BS12) and 55.69 (100BS-12), respectively. The pore volume increased while the modification ratios increased and it indicated the effect of phenol on modified soil was enhanced. The NPV of blocking phenol was in order of CK < 50BS12 < 100BS12 at V/Vo as 1.78, 14.83 and 17.98 at C/Co $(0-0.009)$ in Figure 3. Table 3 showed the $R$-value of CK, 50BS-12 and 100BS-12 (50 ppm, pH = 7, and ionic strength $=0.1 \mathrm{~mol} / \mathrm{l}$ ) was bigger than 1 and $R^{2}$ was closer to 1 , so it was proved that the phenol in soil was blocked. The $R$-value of modified soil was larger while modification ratios increased. The linear correlation equation $R$ and $\mathrm{T}_{0.5}$ of modified soil were $R=0.0566 \mathrm{~T}_{0.5}+1.1396, R^{2}=0.9942$, so it indicated that the duration of transport was longer while $R$ became larger. The $R$-value of CK

Table 2. Transport parameters for $\mathrm{Cl}^{-}$in BTC fitted by EM model with $v$ and $D$ fixed.

\begin{tabular}{|c|c|c|c|c|c|}
\hline Soils & $\begin{array}{c}\text { Average of pore } \\
\text { water velocity } \\
\qquad(\mathrm{cm} / \mathrm{h})\end{array}$ & $\begin{array}{c}\text { Average } \\
\text { penetration } \\
\text { time } \mathrm{T}_{0.5}(\mathrm{~h})\end{array}$ & $\begin{array}{c}\text { Dispersion } \\
\text { coefficient } D \\
\left(\mathrm{~cm}^{2} / \mathrm{h}\right)\end{array}$ & $\begin{array}{c}\text { Retardation } \\
\text { factor } \\
R\end{array}$ & $\begin{array}{c}\text { Correlation } \\
\text { coefficient } R^{2}\end{array}$ \\
\hline CK & 10.69 & 2.27 & 5.242 & 0.7518 & $0.998^{\star * *}$ \\
\hline $50 \mathrm{BS}-12$ & 4.49 & 5.29 & 1.908 & 0.7971 & $0.996^{* * *}$ \\
\hline 100BS-12 & 5.11 & 5.59 & 3.577 & 0.8622 & $0995^{\star \star \star}$ \\
\hline
\end{tabular}

Note: ${ }^{* * *}$ indicates that the correlation coefficient is significant at $\mathrm{P}<0.01$.

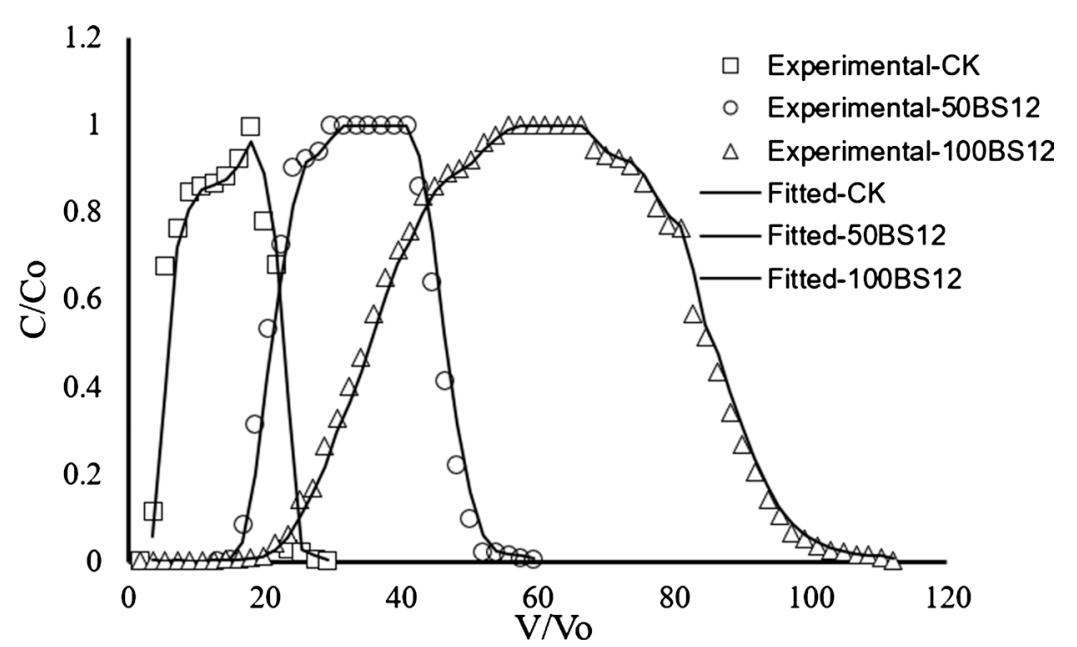

Figure 3. The BTCs of transport and washout: $\mathrm{pH}=7$, ionic strength $=0.1 \mathrm{~mol} / \mathrm{l}, 50 \mathrm{ppm}$ of phenol in CK, 50BS-12 and 100BS-12. 
Table 3. Transport parameters for phenol in BTC fitted by NEM model with $V$ and $D$ fixed: 3 concentrations, $3 \mathrm{pH}$ and 3 ionic strengths.

\begin{tabular}{|c|c|c|c|c|c|c|c|c|}
\hline Soils & $\begin{array}{c}\text { Concentration } \\
(\mathrm{ppm})\end{array}$ & $\mathrm{pH}$ & $\begin{array}{c}\text { Ionic } \\
\text { strength } \\
(\mathrm{mol} / \mathrm{l})\end{array}$ & $\begin{array}{l}\text { Average } \\
\text { pore water } \\
\text { velocity } V \\
(\mathrm{~cm} / \mathrm{h})\end{array}$ & $\begin{array}{c}\text { Average } \\
\text { penetration } \\
\text { time } \mathrm{T}_{0.5}\end{array}$ & $\begin{array}{c}D \\
\left(\mathrm{~cm}^{2} / \mathrm{h}\right)\end{array}$ & $\begin{array}{c}\text { Retardati } \\
\text { on factor } \\
R\end{array}$ & $\begin{array}{c}\text { Correlation } \\
\text { coefficient } \\
R^{2}\end{array}$ \\
\hline \multirow{7}{*}{ CK } & 50 & 4 & 0.1 & 14.761 & 2.266 & 4.707 & 0.9648 & $0.998^{\star * *}$ \\
\hline & 50 & 7 & 0.1 & 10.077 & 5.64 & 3.134 & 1.337 & $0.995^{\star * *}$ \\
\hline & 50 & 7 & 0.01 & 14.58 & 2.8 & 6.878 & 0.9091 & $0.998^{\star * *}$ \\
\hline & 50 & 7 & 0.001 & 15.15 & 2.8 & 4.48 & 0.8856 & $0.999^{* * *}$ \\
\hline & 50 & 10 & 0.1 & 7.025 & 6.75 & 2.406 & 1.399 & $0.997^{* * *}$ \\
\hline & 200 & 7 & 0.1 & 11.28 & 4.71 & 8.704 & 0.9811 & $0.996^{* * *}$ \\
\hline & 500 & 7 & 0.1 & 5.93 & 8.85 & 0.1018 & 1.222 & $0.999^{* * *}$ \\
\hline \multirow[t]{4}{*}{ 50BS- 12} & 50 & 7 & 0.1 & 2.9 & 44.14 & 0.8869 & 4.085 & $0.997^{\star * *}$ \\
\hline & 50 & 4 & 0.1 & 1.898 & 53.58 & 0.2622 & 6.805 & $0.985^{\star * *}$ \\
\hline & 50 & 7 & 0.1 & 2.552 & 98.45 & 0.3735 & 7.048 & $0.995^{\star * *}$ \\
\hline & 50 & 7 & 0.01 & 4.769 & 39.86 & 0.2036 & 6.211 & $0.990^{* * *}$ \\
\hline \multirow[t]{4}{*}{ 100BS- 12} & 50 & 7 & 0.001 & 6.99 & 29.15 & 0.2402 & 6.197 & $0.996^{* * *}$ \\
\hline & 50 & 10 & 0.1 & 3.425 & 33.33 & 1.731 & 6.917 & $0.989^{* * *}$ \\
\hline & 200 & 7 & 0.1 & 2.057 & 95.591 & 0.0212 & 6.597 & $0.995^{\star * *}$ \\
\hline & 500 & 7 & 0.1 & 2.281 & 96.94 & 1.129 & 6.381 & $0.998^{* * *}$ \\
\hline
\end{tabular}

Note: ${ }^{* * *}$ indicates that the correlation coefficient is significant at $\mathrm{P}<0.01$.

was smaller than (50BS-12) 3.05 and (100BS-12) 5.27 times. Because the BS12 modified soil with long chain carbon was changed the surfactant from hydrophilic to hydrophobic and the adsorption mechanism was enhanced with increasing modified proportion [24]. By adding more details, researchers proved that high organic matter content, microstructure and surfactant in soil greatly impacted on pollutants migration [25] [26] [27]. Therefore, modified soil greatly enhanced blocking ability while modification ratios were increased.

\subsection{Effect of Concentrations}

The BTCs of various phenol's concentrations of CK and 100BS-12 was shown in Figure 4, and its results of transport parameters were also shown in Table 3. The NPV at various phenol's concentration in CK was 17.89 (50 ppm), 11.24 (200 ppm) and 11.94 (500 ppm); 100BS-12 was 55.69 (50 ppm), 44.15 (200 ppm) and $47.26(500 \mathrm{ppm})$.

The $R$-value of CK didn't significantly change in each concentration. This was because the unmodified soil was a weakness to block and easily polluted. The $R$-value of 100BS-12 was bigger than $R$ of CK as 6, 7 times, while high concentration was $500 \mathrm{ppm}$ and the $R$-value was in order of $R_{50 \mathrm{ppm}}>R_{200 \mathrm{ppm}}>R_{500 \mathrm{ppm}}$. It indicated $R$-value became smaller while the high concentration was larger. 

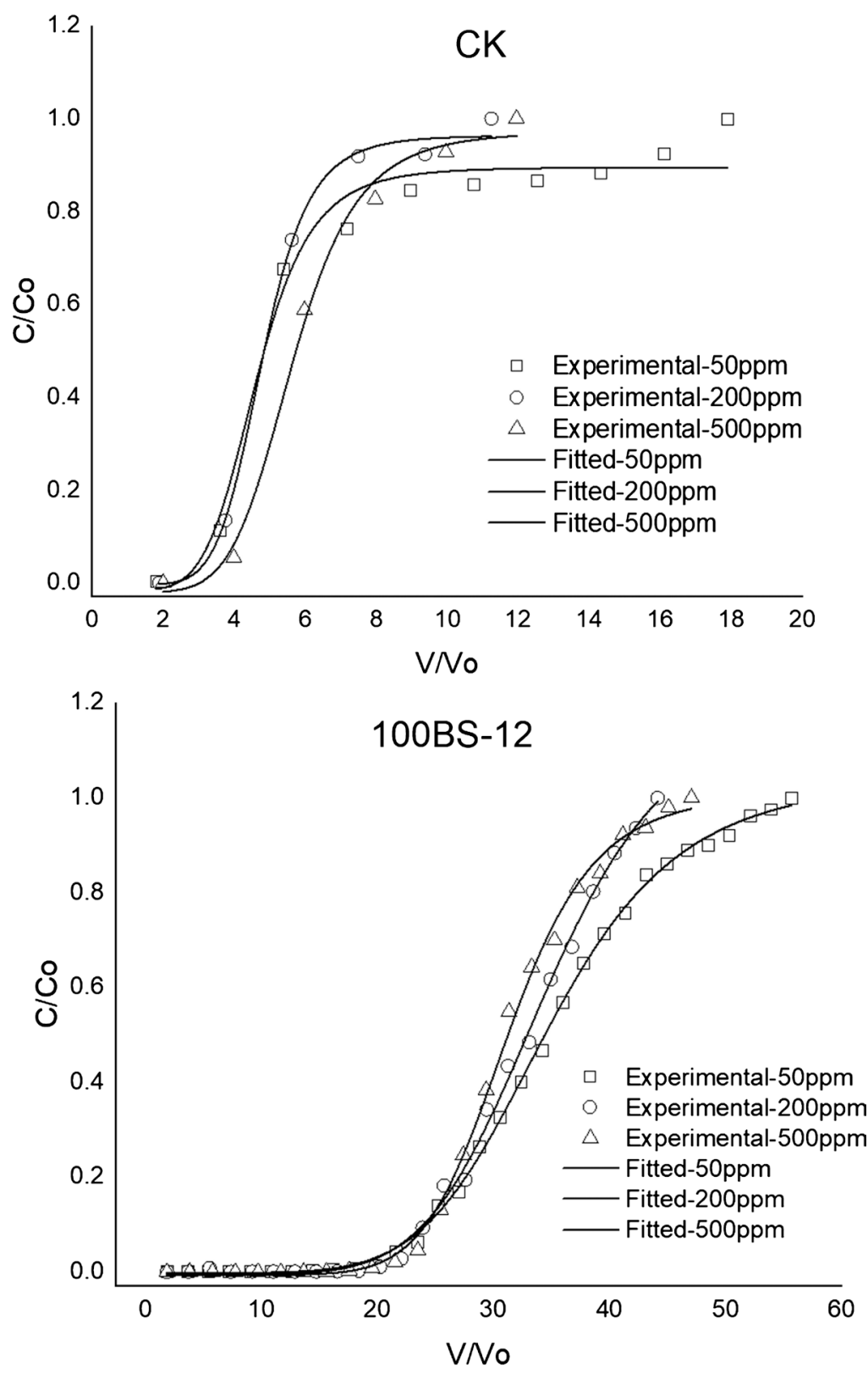

Figure 4. The BTCs of transport on CK and 100BS-12 in different concentrations, $\mathrm{pH}=$ 7 , and ionic strength $0.1 \mathrm{~mol} / \mathrm{l}$.

Therefore, the retardation ability of modified soil strongly blocked with high concentration.

\subsection{Effect of $\mathrm{pH}$}

The BTCs of various $\mathrm{pH}$ (4, 7 and 10) on phenol in CK and 100BS-12 was shown in Figure 5. As seen the results in Table 3, the $V$ value of CK decreased and $R$-value increased while the $\mathrm{pH}$ was high. It showed that $\mathrm{pH}$ had little effect on CK. The parameter of $R$-value for $\mathrm{pH}$ on phenol in 100BS-12 didn't change remarkably but only $V$ value increased with increasing $\mathrm{pH}$ value, respectively. Thus, the various $\mathrm{pH}$ on the transport of phenol through CK and 100BS-12 only 

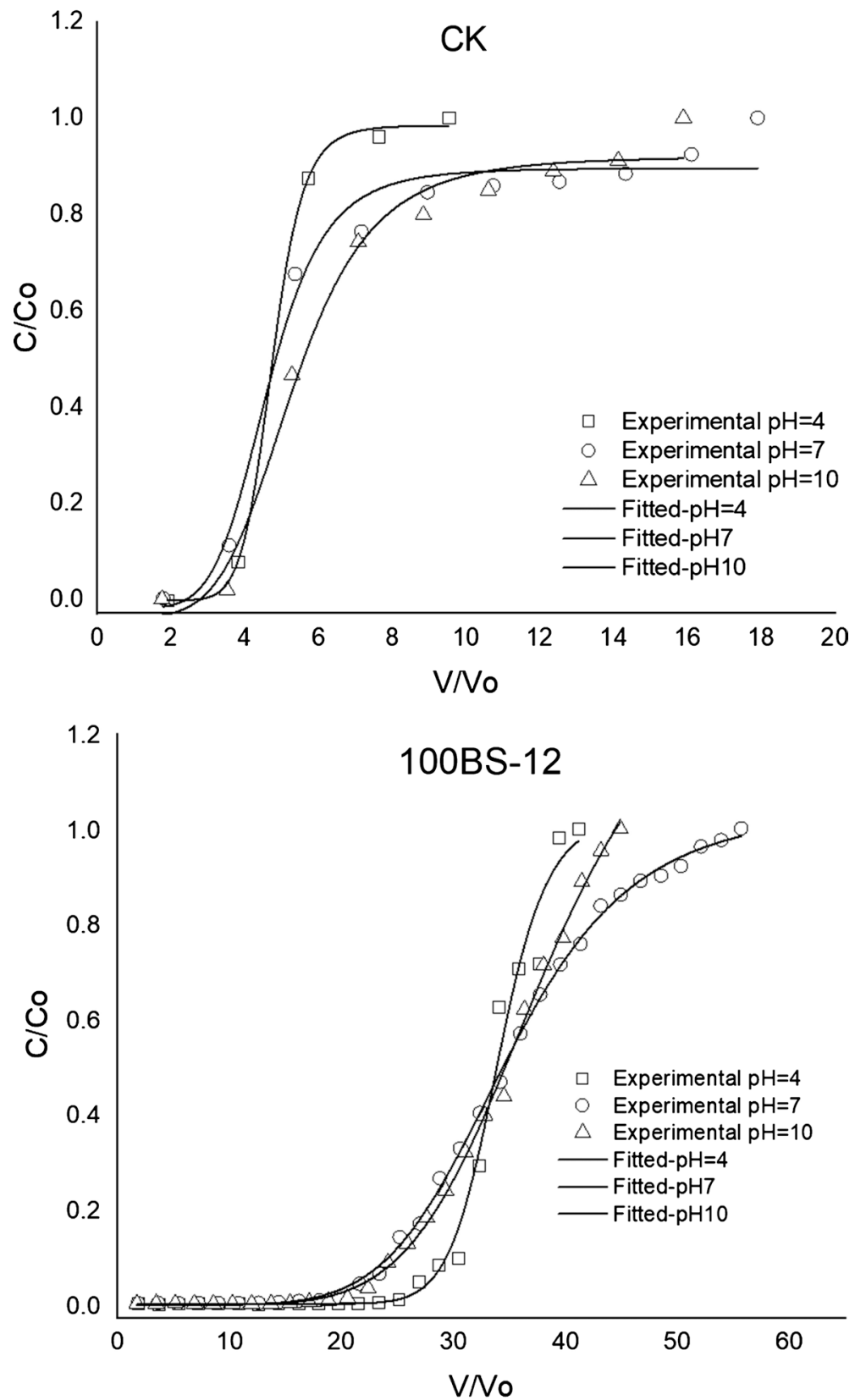

Figure 5. The BTCs of transport on CK and 100BS-12 in various $\mathrm{pH}, 50 \mathrm{ppm}$ and ionic strength $0.1 \mathrm{~mol} / \mathrm{l}$

changed the number of charges in soils [15] [28]. At the same of pH value, we observed that the $R$-value, $\mathrm{T}_{0.5}$ of $\mathrm{CK}$ and $100 \mathrm{BS}-12$ were different and it indicated that the 100BS-12 strongly blocked phenol. However, the blocking phenol was strongly retarded in 100BS-12 at $\mathrm{pH} 7$.

\subsection{Effect of Ionic Strength}

The BTCs of the various ionic strength of phenol through CK and 100BS-12 was shown in Figure 6. Table 3 showed that the $R$-value of CK and 100BS-12 both was $R_{0.1}>R_{0.01}>R_{0.001}$ and various ionic strength of phenol migration obviously 

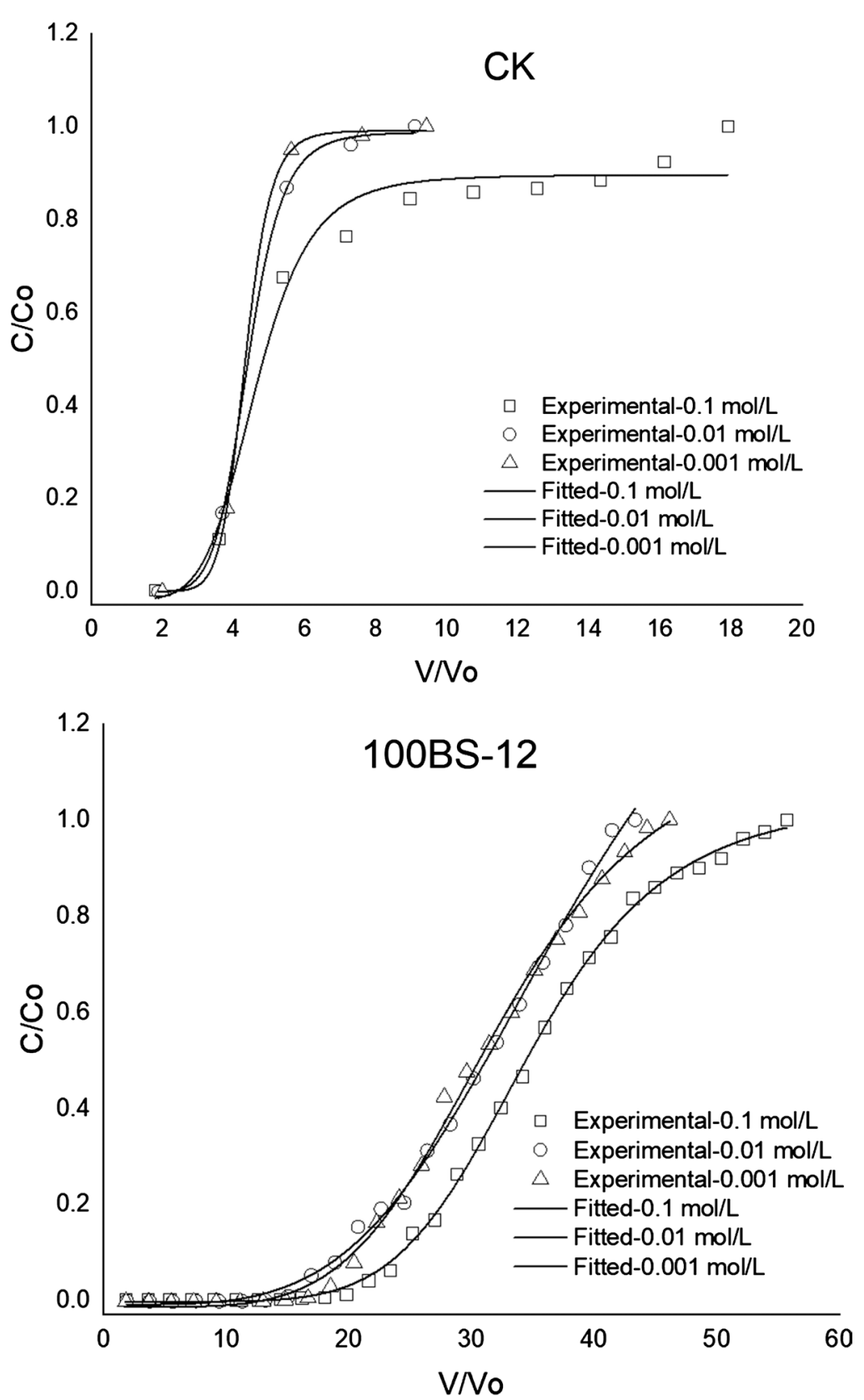

Figure 6. The BTCs of transport on CK and 100BS-12 in various ionic strength, $50 \mathrm{ppm}$, and $\mathrm{pH}=7$.

affected. The parameter of $v$ in CK and 100BS-12 both was faster when the ionic strength decreased. This is because the mechanism increasing of ionic strength could increase aggregation adsorbent and decreased the electrostatic force of pollutants migration [29] [30] [31] [32] [33]. Therefore, the decreasing of ionic strength could penetrate faster and the adsorption of phenol was reduced.

\subsection{Wash Out of Phenol in Unmodified Soil, and Modified Soil}

When phenol almost penetrated in soils, the solution was changed to $\mathrm{NaCl}$ to wash out phenol. Figure 2 showed the pore volume in CK, 50BS-12 and 100BS-12 
started at 19.86, 31.5 and 57.49. Using the CXTFIT model as a non-equilibrium model (NEM) for fitting the washout curve and the parameters of phenol washout was shown in Table 4 . The $R_{\mathrm{w}}$ value of washout was bigger than $R$-value of transport, and it indicated the phenol keeping in soil was difficult to wash out. The $R_{\mathrm{w}}$ value in soils was in order of CK $<50 \mathrm{BS}-12<100 \mathrm{BS}-12$, and the $R_{\mathrm{w}}$ of 100BS-12 was bigger than $\mathrm{CK}$ as 17.27 times. The linear analysis equation between residual retention in soil and saturation amount in soil was $y=6.5541 x+$ $0.2064, R^{2}=0.771^{\star}(\mathrm{P}<0.01)$, it indicated that the residual retention in soil and saturation amount in soil was related each other. So that, the high modification ratio in soil could hold phenol and amount of pollutant not only was increasingly adsorbed but also the mass of soil was increased with the amount of pollutant after washing out [18] [28]. The residual retention in 50BS-12 and 100BS-12 was bigger than CK 6.98 and 7.21 times. It demonstrated that the surface was changed to amphoteric surfactant by covering BS-12, and BS-12 surfactant obviously affected phenol migration in the column experiment. Unit holding rate in each soil was CK (41.37\%), 50BS-12 (83.13\%) and 100 BS-12 (52.06\%).

Last, the lou soil with high modification ratio had a better adsorption capacity for phenol migration. As seen the result with high blocking, high residual retention, and duration, it was confirmed that modified surface soil significantly reduced and blocked the pollutant migrant and also provided high organic matter to soil.

\section{Conclusion}

The unmodified soil as lou soil was changed surfactant to amphoteric modified soil (BS-12). Transport of $\mathrm{NaCl}$ on modified soil slightly affected by comparing to unmodified soil and phenol migration was strongly blocked while the soil was modified by the amphoteric surfactant. The retardation capacity of soil was improved when the modification ratio increased. Using the CXTFIT model was fitted by the equilibrium model (EM) for $\mathrm{Cl}^{-}$parameter and non-equilibrium model (NEM) for phenol parameter. The various of phenol's concentrations could reduce retardation ability of soil modification with high phenol concentration. The $\mathrm{pH}$ of 4 and 10 didn't affect to phenol migration and the only $\mathrm{pH} 7$ on phenol migration proved too high retardation ability in the soil modification. The decreasing ionic strength could affect phenol penetration in soil sample and the

Table 4. Washout parameters for phenol in BTC fitted by NEM model with $v_{\text {wash }}$ and D fixed and simulate phenol curve in CURVE EXPERT by integrating curve area.

\begin{tabular}{ccccccccc}
\hline Soils & $\begin{array}{c}V_{\text {wash }} \\
(\mathrm{cm} / \mathrm{h})\end{array}$ & $\begin{array}{c}\text { Duration } \\
(\mathrm{h})\end{array}$ & $\begin{array}{c}\text { Saturation } \\
\text { amount } \\
/ \mathrm{mmol}\end{array}$ & $\begin{array}{c}\text { Washout } \\
\text { amount } \\
/ \mathrm{mmol}\end{array}$ & $\begin{array}{c}\text { Residual } \\
\text { retention } \\
\text { in soil } \\
(\mathrm{mmol} / \mathrm{kg})\end{array}$ & $\begin{array}{c}\text { Unit } \\
\text { holding } \\
\text { rate }(\%)\end{array}$ & $R_{\mathrm{w}}$ & $R^{2}$ \\
\hline CK & 8.688 & 11.27 & 0.066 & 0.039 & 0.3245 & $41.37 \%$ & 5.786 & $0.826^{* * *}$ \\
50BS-12 & 2.219 & 29.73 & 0.2181 & 0.036 & 2.2668 & $83.13 \%$ & 45.300 & $0.880^{* * *}$ \\
100 BS-12 & 3.628 & 158.46 & 0.3731 & 0.1788 & 2.3404 & $52.06 \%$ & 99.980 & $0.931^{* * *}$ \\
\hline
\end{tabular}


duration of transport was short period and $v$ become faster. The residual retention of modified soil could hold phenol more than CK. The last at all, modifying soil with amphoteric surfactant in the column experiment greatly blocked pollutant migration. Moreover, it is confirmed that the blocking ability to organic pollutants of subsurface soil modified by BS-12 was enhanced through simulation test; subsurface soil after modification can significantly slow the speed of organic pollutants infiltration with soil water and based on previous research it has demonstrated that the soil with surfactant can improve physical soil, and water retention in pore soil, and prevent runoff and soil erosion.

\section{Acknowledgements}

The authors are deeply grateful to Dr. Zhaofu Meng, College of Natural Resources and Environment, Northwest A\&F University, Yangling 712100, China, for his kindly help and enthusiasm in guiding this study from conception to its completion.

\section{Funding}

This research was funded by the financial support from the National Natural Science Foundation of China (No.41271244) and the Key research-development Project in Shaanxi Province, China (No.2017SF-385).

\section{Conflicts of Interest}

The authors declare no conflicts of interest regarding the publication of this paper.

\section{References}

[1] George, R., Joy, V., Aiswarya, S., and Jacob, P.A. (2014) Treatment Methods for Contaminated Soils-Translating Science into Practice. International Journal of Education and Applied Research, 4, 17-19.

[2] Arcibar-Orozco, J.A., Rangel-Mendez, J.R. and Diaz-Flores, P.E. (2014) Simultaneous Adsorption of $\mathrm{Pb}(\mathrm{Ii})-\mathrm{Cd}(\mathrm{Ii}), \mathrm{Pb}(\mathrm{Ii})$-Phenol, and $\mathrm{Cd}(\mathrm{Ii})-\mathrm{Phenol}$ by Activated Carbon Cloth in Aqueous Solution. Water, Air, \& Soil Pollution, 226, Article ID: 2197. https://doi.org/10.1007/s11270-014-2197-1

[3] Lin, S.-H. and Juang, R.-S. (2009) Adsorption of Phenol and Its Derivatives from Water Using Synthetic Resins and Low-Cost Natural Adsorbents: A Review. Journal of Environmental Management, 90, 1336-1349. https://doi.org/10.1016/j.jenvman.2008.09.003

[4] Banat, F.A., Al-Bashir, B., Al-Asheh, S. and Hayajneh, O. (2000) Adsorption of Phenol by Bentonite. Environmental Pollution, 107, 391-398.

https://doi.org/10.1016/S0269-7491(99)00173-6

[5] Bachir, M., Salah, M.M., El-fala, B.Z. and Soulard, M. (2014) Conférence International des Sciences des Matériaux (CSM 8) Beyrouth (Liban) Possibility of Adsorption of Phenols on One Natural Bentonite. Physics Procedia, 55, 356-366. https://doi.org/10.1016/j.phpro.2014.07.052

[6] Boyd, S.A., Lee, J.-F. and Mortland, M.M. (1988) Attenuating Organic Contaminant 
Mobility by Soil Modification. Nature, 333, 345-347.

https://doi.org/10.1038/333345a0

[7] Gao, B., Wang, X., Zhao, J. and Sheng, G. (2001) Sorption and Cosorption of Organic Contaminant on Surfactant-Modified Soils. Chemosphere, 43, 1095-1102. https://doi.org/10.1016/S0045-6535(00)00187-9

[8] Meng, Z., Zhang, Y. and Li, R. (2005) Effects of Modification of Manural Loessial Soil by Adding Organic Compounds on Phenol Adsorption and Its Thermodynamic Characteristics. Acta Scientiae Circumstantiae, 25, 1365-1372.

[9] Meng, Z.-F., Zhang, Y.-P. and Guo, Z. (2008) Surface Characteristics of Organic Modified Soil I CEC and Specific Surface Area. Acta Pedologica Sinica, 45, 370-374.

[10] Zhou, W., Zhu, K., Zhan, H., Jiang, M. and Chen, H. (2003) Sorption Behaviors of Aromatic Anions on Loess Soil Modified with Cationic Surfactant. Journal of Hazardous Materials, 100, 209-218. https://doi.org/10.1016/S0304-3894(03)00112-2

[11] Meng, Z.-F., Zhang, Y.-P. and Zhang, Z.-Q. (2008) Simultaneous Adsorption of Phenol and Cadmium on Amphoteric Modified Soil. Journal of Hazard Mater, 159, 492-498. https://doi.org/10.1016/j.jhazmat.2008.02.045

[12] Bai, J.-F., Meng, Z.-F., Liu, Y.-H., Qin, P.-X., Zheng, P.-Y., Xun, L.-L. and Guo, C.-H. (2010) Adsorption of Phenol on Amphoteric-Cationic Modified Lou Soil. China Environmental Science, 10, 1389-1394.

[13] Adhikari, K., Pal, S., Chakraborty, B., Mukherjee, S.N. and Gangopadhyay, A. (2014) Assessment of Phenol Infiltration Resilience in Soil Media by HYDRUS-1D Transport Model for a Waste Discharge Site. Environmental Monitoring and Assessment, 186, 6417-6432. https://doi.org/10.1007/s10661-014-3864-9

[14] Pal, S., Mukherjee, S. and Ghosh, S. (2014) Application of HYDRUS 1D Model for Assessment of Phenol-Soil Adsorption Dynamics. Environmental Science and Pollution Research, 21, 5249-5261. https://doi.org/10.1007/s11356-013-2467-2

[15] Huang, S., Zhang, R., Zhang, J. and Pan, R. (2009) Effects of pH and Soil Texture on the Adsorption and Transport of Cd in Soils. Science in China Series E: Technological Sciences, 52, 3293-3299. https://doi.org/10.1007/s11431-009-0348-1

[16] Chotpantarat, S., Ong, S.K., Sutthirat, C. and Osathaphan, K. (2011) Effect of pH on Transport of $\mathrm{Pb}^{2+}, \mathrm{Mn}^{2+}, \mathrm{Zn}^{2+}$ and $\mathrm{Ni}^{2+}$ through Lateritic Soil: Column Experiments and Transport Modeling. Journal of Environmental Sciences, 23, 640-648. https://doi.org/10.1016/S1001-0742(10)60417-2

[17] Zhang, X., Tong, J., Hu, B.-X. and Wei, W. (2017) Adsorption and Desorption for Dynamics Transport of Hexavalent Chromium (Cr(VI)) in Soil Column. Environmental Science and Pollution Research, 25, 459-468. https://doi.org/10.1007/s11356-017-0263-0

[18] Di, X., Meng, Z.-F., Yang, S., Cui, X., Xiang, W., Ren, W., Yang, Y.-L., Li, W.-B. and Wu, Q. (2015) Soil Organic Polluted Matter Phenol Migration Characteristics in Modified Loessial Soil. Transactions of the Chinese Society of Agricultural Engineering, 31, 249-255.

[19] Toride, N., Leij, F.J. and van Genuchten, M.T. (1995) The CXTFIT Code for Estimating Transport Parameters from Laboratory or Field Tracer Experiments. U.S. Salinity Laboratory Agricultural Research Service. U.S. Department of Agriculture, Riverside, CA.

[20] Simunek, J., van Genuchten, M.T., Sejna, M., Toride, N. and Leij, F.J. (1999) The Stanmod Computer Software for Evaluating Solute Transport in Porous Media Using Analytical Solutions of Convection-Dispersion Equation. U.S. Salinity Laboratory, U.S. Salinity Laboratory, Agricultural Research Service, U.S. Department of 
Agriculture, Riverside, CA, 4-10.

[21] Chotpantarat, S., Ong, S.K., Sutthirat, C. and Osathaphan, K. (2012) Competitive Modeling of Sorption and Transport of $\mathrm{Pb}^{2+}, \mathrm{Ni}^{2+}, \mathrm{Mn}^{2+}$ and $\mathrm{Zn}^{2+}$ under Binary and Multi-Metal Systems in Lateritic Soil Columns. Geoderma, 189-190, 278-287. https://doi.org/10.1016/j.geoderma.2012.06.032

[22] Fonseca, B., Teixeira, A., Figueiredo, H. and Tavares, T. (2009) Modelling of the Cr(VI) Transport in Typical Soils of the North of Portugal. Journal of Hazard Mater, 167, 756-762. https://doi.org/10.1016/j.jhazmat.2009.01.049

[23] Yang, H.-N., Meng, Z.-F., and Yang, F. (2009) $\mathrm{Cd}^{2+}$ Transport in Amphoteric Modified Lou Soil. Chinese Journal of Soil Science, 40, 400-405.

[24] Meng, Z.-F., Zhang, Y.-P. and Wang, G.-D. (2007) Sorption of Heavy Metal and Organic Pollutants on Modified Soils. Pedosphere, 17, 235-245. https://doi.org/10.1016/S1002-0160(07)60030-7

[25] Chen, Y.-X., Chen, H.-L., Xu, Y.-T. and Shen, M.-W. (2004) Irreversible Sorption of Pentachlorophenol to Sediments: Experimental Observations. Environment International, 30, 31-37. https://doi.org/10.1016/S0160-4120(03)00145-4

[26] Woignier, T., Fernandes, P., Soler, A., Clostre, F., Carles, C., Rangon, L. and Lesueur-Jannoyer, M. (2013) Soil Microstructure and Organic Matter: Keys for Chlordecone Sequestration. Journal of Hazard Mater, 262, 357-364. https://doi.org/10.1016/j.jhazmat.2013.08.070

[27] Al-Asheh, S., Banat, F. and Abu-Aitah, L. (2003) Adsorption of Phenol Using Different Types of Activated Bentonites. Separation and Purification Technology, 33, 1-10. https://doi.org/10.1016/S1383-5866(02)00180-6

[28] Zhang, Y.-L., Lin, S.-S., Dai, C.-M., Shi, L. and Zhou, X.-F. (2014) Sorption-Desorption and Transport of Trimethoprim and Sulfonamide Antibiotics in Agricultural Soil: Effect of Soil Type, Dissolved Organic Matter, and pH. Environmental Science and Pollution Research, 21, 5827-5835. https://doi.org/10.1007/s11356-014-2493-8

[29] Wang, S., Hu, J., Li, J. and Dong, Y. (2009) Influence of pH, Soil Humic/Fulvic Acid, Ionic Strength, Foreign Ions and Addition Sequences on Adsorption of $\mathrm{Pb}(\mathrm{II})$ onto GMZ Bentonite. Journal of Hazard Mater, 167, 44-51. https://doi.org/10.1016/j.jhazmat.2008.12.079

[30] Chang, P., Yu, S., Chen, T., Ren, A., Chen, C. and Wang, X. (2008) Effect of pH, Ionic Strength, Fulvic Acid and Humic Acid on Sorption of Th(IV) on Na-Rectorite. Journal of Radioanalytical and Nuclear Chemistry, 274, 153-160. https://doi.org/10.1007/s10967-006-6865-5

[31] Wang, T., Liu, W., Xiong, L., Xu, N. and Ni, J. (2013) Influence of pH, Ionic Strength and Humic Acid on Competitive Adsorption of $\mathrm{Pb}(\mathrm{II}), \mathrm{Cd}(\mathrm{II})$ and $\mathrm{Cr}$ (III) onto Titanate Nanotubes. Chemical Engineering Journal, 215-216, 366-374. https://doi.org/10.1016/j.cej.2012.11.029

[32] He, S., Li, Y., Weng, L., Wang, J., He, J., Liu, Y., Zhang, K., Wu, Q., Zhang, Y. and Zhang, Z. (2018) Competitive adsorption of $\mathrm{Cd}^{2+}, \mathrm{Pb}^{2+}$ and $\mathrm{Ni}^{2+}$ onto $\mathrm{Fe}^{3+}$-Modified Argillaceous Limestone: Influence of $\mathrm{pH}$, Ionic Strength and Natural Organic Matters. Science of the Total Environment, 637-638, 69-78. https://doi.org/10.1016/j.scitotenv.2018.04.300

[33] Zeng, F., He, Y., Lian, Z. and Xu, J. (2014) The Impact of Solution Chemistry of Electrolyte on the Sorption of Pentachlorophenol and Phenanthrene by Natural Hematite Nanoparticles. Science of the Total Environment, 466-467, 577-585. https://doi.org/10.1016/j.scitotenv.2013.07.072 